\title{
Hearing subclassification may predict long-term auditory outcomes after radiosurgery for vestibular schwannoma patients with good hearing
}

\author{
Seyed H. Mousavi, MD, ${ }^{1}$ Ajay Niranjan, MD, ${ }^{1}$ Berkcan Akpinar, BA, ${ }^{3}$ Marshall Huang, BS, ${ }^{3}$ \\ Hideyuki Kano, MD, PhD, ${ }^{1}$ Daniel Tonetti, MD, ${ }^{1}$ John C. Flickinger, MD, ${ }^{2}$ and \\ L. Dade Lunsford, MD',2 \\ Departments of ${ }^{1}$ Neurological Surgery and ${ }^{2}$ Radiation Oncology, University of Pittsburgh Medical Center; and ${ }^{3}$ University of \\ Pittsburgh School of Medicine, Pittsburgh, Pennsylvania
}

\begin{abstract}
OBJECTIVE In the era of MRI, vestibular schwannomas are often recognized when patients still have excellent hearing. Besides success in tumor control rate, hearing preservation is a main goal in any procedure for management of this population. The authors evaluated whether modified auditory subclassification prior to radiosurgery could predict longterm hearing outcome in this population.

METHODS The authors reviewed a quality assessment registry that included the records of 1134 vestibular schwannoma patients who had undergone stereotactic radiosurgery during a 15-year period (1997-2011). The authors identified 166 patients who had Gardner-Robertson Class I hearing prior to stereotactic radiosurgery. Fifty-three patients were classified as having Class I-A (no subjective hearing loss) and 113 patients as Class I-B (subjective hearing loss). Class I-B patients were further stratified into Class I-B1 (pure tone average $\leq 10 \mathrm{~dB}$ in comparison with the contralateral ear; 56 patients), and I-B2 (> $10 \mathrm{~dB}$ compared with the normal ear; 57 patients). At a median follow-up of 65 months, the authors evaluated patients' hearing outcomes and tumor control.

RESULTS The median pure tone average elevations after stereotactic radiosurgery were $5 \mathrm{~dB}, 13.5 \mathrm{~dB}$, and $28 \mathrm{~dB}$ in Classes I-A, I-B1, and I-B2, respectively. The median declines in speech discrimination scores after stereotactic radiosurgery were $0 \%$ for Class I-A ( $p=0.33$ ), $8 \%$ for Class I-B1 ( $p<0.0001$ ), and $40 \%$ for Class I-B2 ( $<<0.0001)$. Serviceable hearing preservation rates were $98 \%, 73 \%$, and $33 \%$ for Classes I-A, I-B1, and I-B2, respectively. GardnerRobertson Class I hearing was preserved in $87 \%, 43 \%$, and $5 \%$ of patients in Classes I-A, I-B1, and I-B2, respectively.

CONCLUSIONS Long-term hearing preservation was significantly better if radiosurgery was performed prior to subjective hearing loss. In patients with subjective hearing loss, the difference in pure tone average between the affected ear and the unaffected ear was an important factor in long-term hearing preservation.
\end{abstract}

http://thejns.org/doi/abs/10.3171/2015.8.JNS151624

KEY WORDS stereotactic radiosurgery; vestibular schwannoma; hearing preservation; Gardner-Robertson Class I

$\mathrm{S}$ TEREOTACTIC radiosurgery (SRS) is the least invasive therapeutic option for patients harboring vestibular schwannomas. ${ }^{13,22}$ Because of the published high rates of tumor control and lower risks compared with other surgical management options, SRS may now be the most commonly used management strategy in the United States for patients with small to moderate size tumors. . $^{13,18,19,24}$ The expansion of MRI facilities has resulted in earlier diagnosis and recognition of tumors at smaller volumes.
Many such patients have no or minimal hearing loss but instead the tumors are discovered incidentally or during evaluations for tinnitus or disequilibrium. ${ }^{6,14,23}$ In recent years some vestibular schwannoma specialists have advised no intervention until the tumor volume increases or new symptoms emerge. Recent reports indicate that SRS leads to a high rate of hearing preservation in patients who have high-level hearing before SRS. ${ }^{18,25} \mathrm{We}$ wished to determine if there were pertinent subclassification factors in 
patients with good hearing that might predict the likelihood of hearing preservation after SRS and thereby argue for earlier intervention before hearing deteriorates.

\section{Methods}

\section{Patient Population}

The University of Pittsburgh Institutional Review Board approved this study. We queried our long-term SRS database registry ${ }^{1}$ to identify 1134 vestibular schwannoma patients who underwent SRS between January 1997 and December 2011. We retrospectively identified 166 patients who met the entry criteria: preoperative audiograms showing Gardner-Robertson ${ }^{5}$ Class I hearing, follow-up longer than 1 year, no prior surgery, the ability to undergo MRI of the head, and no history of neurofibromatosis. The median interval between the last pre-SRS audiogram and date of treatment was 1 month but ranged from 1 day to 6 months, and any patient who reported that hearing had subjectively worsened between the last audiogram and SRS underwent repeat testing. We subclassified these patients into 2 main classes: Class I-A (no subjective hearing loss, 53 patients) and Class I-B (subjective hearing loss, 113 patients). Class I-B was further divided into 2 groups: Class I-B1 (56 patients) if the difference in pure tone average (PTA) in the affected ear was $\leq 10 \mathrm{~dB}$ compared with the unaffected ear, and Class I-B2 (57 patients) if the difference in PTA was $>10 \mathrm{~dB}$ compared with the contralateral ear. The classification is shown in Fig. 1. The median PTAs before SRS of the affected ear were $10 \mathrm{~dB}, 17 \mathrm{~dB}$, and $25 \mathrm{~dB}$ for Classes I-A, I-B1, and I-B2, respectively. The median ages of Class I-A patients were significantly lower than those with Class I-B1 hearing (46 vs 50 years, $\mathrm{p}=0.0052$ ) and Class I-B2 (46 vs 51 years, $\mathrm{p}=0.0023$ ). There was no difference in the median ages of patients in Class I-B1 and I-B2 (50 vs 51 years, $\mathrm{p}=0.65$ ). Other preoperative findings are summarized in Table 1. All patients had House-Brackmann Grade I facial function, ${ }^{12}$ and no patient had trigeminal neuropathy. Patients were referred for SRS at a median interval of 12 months (range from 1 to 156 months) after their initial MRI confirmed a vestibular schwannoma.

\section{Stereotactic Radiosurgery Technique}

SRS was performed as previously described. ${ }^{3}$ An MRIcompatible stereotactic Leksell head frame was applied after administration of local anesthetics and intravenous sedation. Patients underwent high-resolution stereotactic MRI after fiducial system attachment. Contrast-enhanced axial-plane SPGR (spoiled-gradient recalled acquisition in steady state), 0.5 - to 1-mm T2-weighted volume acquisitions, and 3-mm whole head T2-weighted imaging were performed to determine the 3D tumor volume and its relationship to the cochlea. Irradiation isocenters were selected based on the 3D tumor volume including any tumor extension into the internal auditory canal. SRS was performed using the Leksell Gamma Knife. The median tumor margin dose was $12.5 \mathrm{~Gy}$. The median tumor volume was $0.80 \mathrm{~cm}^{3}$ (range $\left.0.1-12.8 \mathrm{~cm}^{3}\right)$.

\section{Follow-Up Evaluations}

Serial MR images were obtained as described previ-

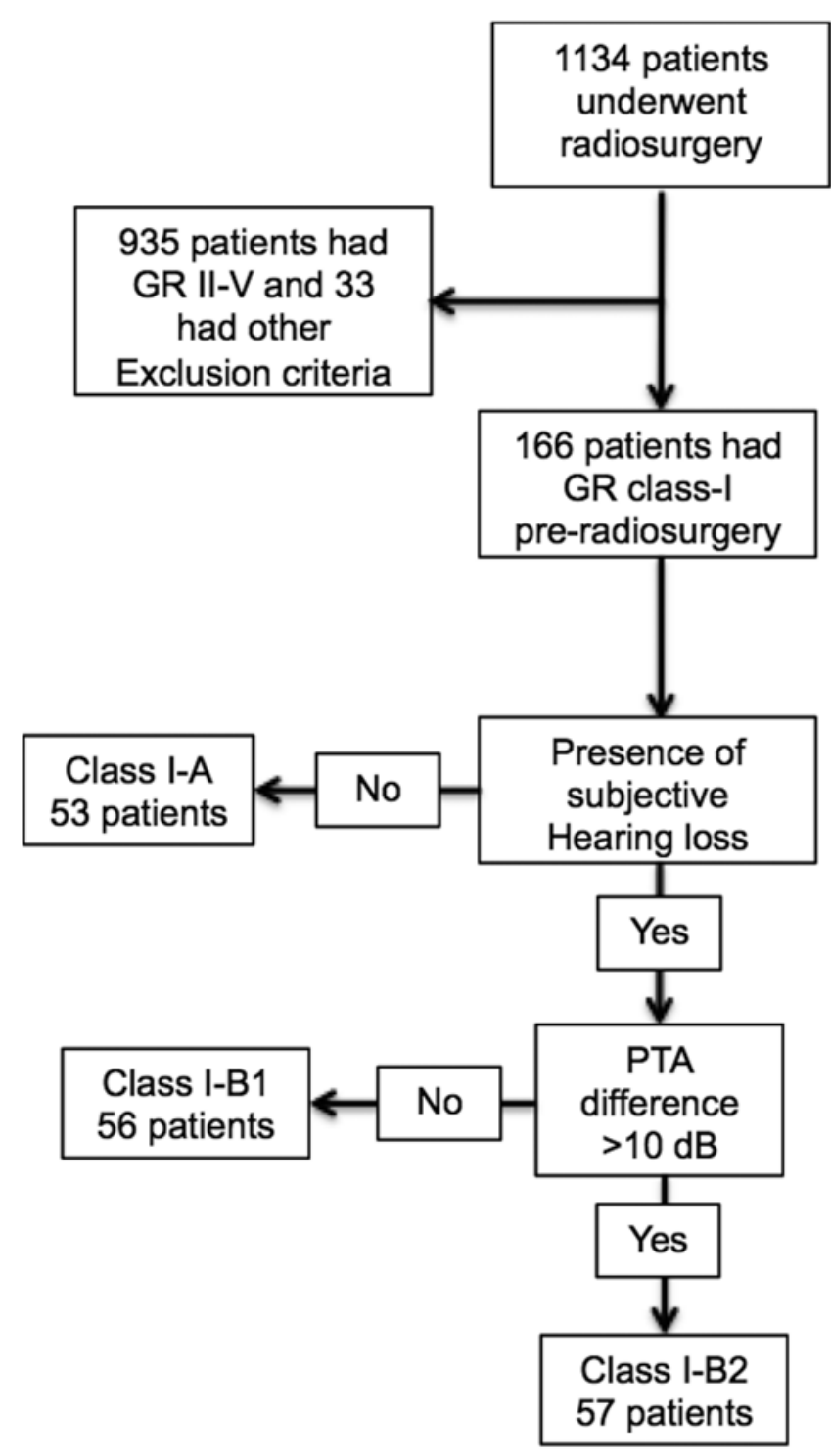

FIG. 1. Diagram of the study population. Patients who met the inclusion criteria reported the absence or presence of subjective hearing loss, and other audiogram was reviewed to compare the PTA in the tumor ear to the contralateral ear. They then were divided into 3 classes: I-A, I-B1, and I-B2. GR = Gardner-Robertson.

ously. ${ }^{18}$ Audiograms were requested routinely at either 6-month or 1-year intervals unless a patient reported additional hearing dysfunction during the observation period. Such patients were then requested to undergo repeat MRI and audiograms. The tumor volume was measured as previously described, ${ }^{15}$ and imaging was also used to assess any adverse radiation effects in the brain adjacent to the tumor. Tumor progression was defined as a $>25 \%$ increase in tumor volume. Hearing evaluation was based on Gardner-Robertson classification. ${ }^{5}$ The percentage of patients with $>20$-dB elevation in PTA and a $>20 \%$ decrease in speech discrimination score (SDS) were also evaluated. A physician, other than the operating surgeon, assessed the SRS outcomes for analysis purposes. Follow-up was terminated if surgical removal of the tumor was performed for any reason in the follow-up period. The median follow- 
TABLE 1. Characteristics of the 166 vestibular schwannoma patients at the time of SRS*

\begin{tabular}{|c|c|c|c|c|}
\hline Characteristic & Class I-A & Class I-B1 & Class I-B2 & Overall \\
\hline \multicolumn{5}{|l|}{ Age in yrs } \\
\hline Median & 46 & 50 & 51 & 49 \\
\hline Range & 20 to 71 & 25 to 71 & 28 to 68 & 20 to 71 \\
\hline \multicolumn{5}{|l|}{ Sex } \\
\hline Male & $19(36 \%)$ & $27(48 \%)$ & $35(61 \%)$ & $81(49 \%)$ \\
\hline Female & $34(64 \%)$ & $29(52 \%)$ & $22(39 \%)$ & $85(51 \%)$ \\
\hline \multicolumn{5}{|l|}{ Presenting symptoms before SRS } \\
\hline Hearing loss only & 0 & 10 & 18 & 28 \\
\hline Observational management before hearing loss onset & 0 & 21 & 18 & 39 \\
\hline Tinnitus & 21 & 0 & 0 & 21 \\
\hline Tinnitus + hearing loss & 0 & 28 & 28 & 56 \\
\hline Tinnitus + other symptoms & 12 & 0 & 0 & 12 \\
\hline Hearing loss + other symptoms & 0 & 18 & 11 & 29 \\
\hline Vertigo & 4 & 0 & 0 & 4 \\
\hline Imbalance & 1 & 0 & 0 & 1 \\
\hline Trigeminal neuropathy & 0 & 0 & 0 & 0 \\
\hline Facial neuropathy & 1 & 0 & 0 & 1 \\
\hline Headache & 3 & 0 & 0 & 3 \\
\hline Incidental & 11 & 0 & 0 & 11 \\
\hline \multicolumn{5}{|l|}{ PTA (dB) } \\
\hline \multicolumn{5}{|l|}{ Tumor-affected ear } \\
\hline Median & 10 & 17 & 25 & 17 \\
\hline Range & 0 to 30 & 5 to 28 & 12 to 30 & 0 to 30 \\
\hline \multicolumn{5}{|l|}{ Non-tumor-affected ear } \\
\hline Median & 7 & 10 & 9 & 9.5 \\
\hline Range & 0 to 23 & 0 to 25 & 0 to 18 & 0 to 25 \\
\hline \multicolumn{5}{|l|}{ Difference in PTA, tumor side vs normal side (dB) } \\
\hline Median & 2 & 5 & 15 & 7 \\
\hline Range & -8 to 23 & -5 to 15 & 11 to 23 & -8 to 23 \\
\hline \multicolumn{5}{|l|}{ SDS $(\%)$} \\
\hline \multicolumn{5}{|l|}{ Tumor-affected ear } \\
\hline Median & 100 & 96 & 92 & 96 \\
\hline Range & 82 to 100 & 70 to 100 & 76 to 100 & 70 to 100 \\
\hline \multicolumn{5}{|l|}{ Non-tumor-affected ear } \\
\hline Median & 100 & 100 & 100 & 100 \\
\hline Range & 92 to 100 & 90 to 100 & 80 to 100 & 80 to 100 \\
\hline \multicolumn{5}{|l|}{ Tumor vol $\left(\mathrm{cm}^{3}\right)$} \\
\hline Median & 0.74 & 0.69 & 1.0 & 0.80 \\
\hline Range & 0.12 to 12.8 & 0.10 to 9.8 & 0.12 to 7.7 & 0.10 to 12.8 \\
\hline \multicolumn{5}{|l|}{ Details of SRS, Gy } \\
\hline \multicolumn{5}{|l|}{ Tumor marginal dose } \\
\hline Median & 12.5 & 12.5 & 12.5 & 12.5 \\
\hline Range & 12 to 13 & 12 to 13 & 12 to 13 & 12 to 13 \\
\hline \multicolumn{5}{|l|}{ Maximum dose } \\
\hline Median & 25 & 25 & 25 & 25 \\
\hline Range & 17.8 to 26 & 18.6 to 26 & 20.8 to 26$)$ & 17.8 to 26 \\
\hline
\end{tabular}

\footnotetext{
* Values represent number of patients unless indicated otherwise.
} 
up period was 65 months (range $12-183$ months). The median follow-ups for patients in Classes I-A, I-B1, and I-B2 were 66,67 , and 65 months, respectively.

\section{Statistical Analysis}

Kaplan-Meier survival analysis was carried out to calculate rates of hearing preservation in each Gardner-Robertson Class I subclass. Patients were censored when lost to follow-up or at the time of an event such as change in hearing status (loss of serviceable hearing, loss of Gardner-Robertson Class I hearing, > 20\% elevation in PTA, $>20 \%$ decrease in SDS). The log-rank test was used to assess differences in survival curves. Cox regression was used for multivariate analyses to calculate significant interactions between hearing preservation rates and related factors (age, sex, and detection of preoperative sensory dysfunction). A p value $<0.05$ was defined as statistically significant. Comparisons between variable groups were performed where appropriate using the Fisher exact test. A comparison of continuous variables was performed using the Mann-Whitney U-test, again with a probability level $<0.05$ set as significant.

\section{Results \\ Tumor Control}

At the time of last follow-up, tumor volumes regressed in 96 patients (58\%), remained stable in 57 (34\%), and became stable after minimal expansion in $10(6 \%)$. Three patients $(2 \%)$ had sustained growth and underwent tumor removal. Patient outcomes after SRS are shown in Table 2.

\section{Speech Discrimination Scores}

The median decrease in SDS was $0 \%$ for Class I-A ( $p=0.33$, Mann-Whitney U-test), $8 \%$ for Class I-B1; $p$ $<0.0001$, Mann-Whitney U-test) and 40\% (p < 0.0001, Mann-Whitney U-test) for Class I-B2 (Table 2). Class I-A had a significantly lower rate of more than $20 \%$ decline in SDS ( $<<0.0001, \log$-rank test) than Class I-B1, and Class I-B1 had a lower rate of more than $20 \%$ decline in SDS (p $<0.0001$, log-rank test) than Class I-B2 (Fig. 2 left). This difference remained significant even after controlling for hearing decline in the normal ear (by subtracting the SDS change in the normal ear compared with the tumor-affected ear).

\section{Pure Tone Averages}

The median PTA increases for Classes I-A, I-B1, and I-B2 were $5 \mathrm{~dB}, 13.5 \mathrm{~dB}$, and $28 \mathrm{~dB}$, respectively. We also evaluated the percentage of patients in each subclass who experienced $>20$-dB elevation in PTA. Class I-A patients had a significantly lower rate of PTA elevation $>20 \mathrm{~dB}$ $(\mathrm{p}=0.001$ log-rank test) than Class I-B1 patients. Class I-B1 patients had a lower rate of PTA elevation $>20 \mathrm{~dB}$ ( $p<0.0001$, log-rank test) than Class I-B2 patients (Fig. 2 right). This difference remained significant even after controlling for hearing decline in the contralateral ear.

\section{Preservation of Gardner-Robertson Class I Hearing}

Forty-six patients (87\%) in Class I-A, 24 patients $(43 \%)$ in Class I-B1, and 3 patients (5\%) in Class I-B2 re- tained Gardner-Robertson Class I hearing after SRS. The Gardner-Robertson Class I hearing preservation rate was significantly higher for Class I-A patients than for Class I-B1 patients ( $\mathrm{p}<0.0001)$. The Gardner-Robertson Class I hearing preservation rate was significantly higher for Class I-B1 than for Class I-B2 patients $(\mathrm{p}<0.0001)$ (Fig. 3 left). The 1-year, 5-year, and 10-year actuarial rates of Gardner-Robertson Class I hearing preservation for patients who presented with Gardner-Robertson Class I-A were $96 \%, 87 \%$, and $72 \%$, respectively. The 1 -year, 5-year, and 10-year rates of Gardner-Robertson Class I hearing preservation for patients who presented with GardnerRobertson Class I-B1 were $73 \%, 39 \%$, and 24\%, respectively. The 1-year, 5-year, and 10-year rates of GardnerRobertson Class I hearing preservation for patients who presented with Gardner-Robertson Class I-B2 hearing were $59 \%, 1 \%$, and $0 \%$, respectively.

\section{Preservation of Serviceable Hearing}

Serviceable hearing (Gardner-Robertson Classes I and II) was preserved in 52 patients $(98 \%)$ with Class I-A hearing, 41 patients (73\%) with Class I-B1 hearing, and 19 patients (33\%) with Class I-B2 hearing. Class I-A patients had significantly higher serviceable hearing preservation rates $(\mathrm{p}<0.0001)$ than Class I-B1 patients. Class I-B1 patients had significantly better serviceable hearing ( $\mathrm{p}<0.0001$, log-rank test) after SRS (Fig. 3 right) compared with Class I-B2 patients. The 1-year, 5-year, and 10 -year rates of serviceable hearing preservation for Class I-A were $100 \%, 100 \%$, and $92 \%$, respectively. The 1 -year, 5 -year, and 10-year rates of serviceable hearing preservation for Class I-B1 were $82 \%, 71 \%$, and $57 \%$, respectively. The 1-year, 5-year, and 10-year actuarial rates of serviceable hearing preservation for Class I-B2 were $65 \%, 35 \%$, and $26 \%$, respectively.

\section{Propensity Score Adjustment}

We performed patient matching to balance the covariates and to reduce potentially confounding effects. We performed multivariate proportional hazards regression analysis to correlate serviceable hearing preservation with several factors, which included the pre-SRS hearing status (Classes I-A, I-B1, and I-B2), age, sex, symptom duration, and margin dose and tumor volume. Serviceable hearing preservation was significantly associated with the preSRS hearing class $(\mathrm{p}<0.0001)$, younger age, and female sex. Tumor size was not associated with hearing preservation in this patient population.

We sought to adjust for selection factors in choosing patients with better hearing for SRS. Through multivariate stepwise logistic regression analysis of Class I-A hearing status, we found that females and younger patients were significantly more likely to be in Class I-A. Sixty-four percent of patients in Class I-A were female compared with $45 \%$ of patients in Class I-B ( $p=0.027)$. The mean age of patients in Class I-A was 44.4 years compared with 50.8 years in Class I-B $(p=0.001)$. We constructed propensity scores accounting for the higher propensity of female and younger patients having Class I-A hearing and then added it to the Cox proportional hazards model for serviceable 
TABLE 2. Hearing and clinical outcome after SRS

\begin{tabular}{|c|c|c|c|c|}
\hline Outcome & Class I-A & Class I-B1 & Class I-B2 & Total \\
\hline \multicolumn{5}{|c|}{ Total no. of pts in GR Class II at FU (\% of total) } \\
\hline $1 \mathrm{yr}$ & $3(6 \%)$ & $6(11 \%)$ & $5(9 \%)$ & $14(8 \%)$ \\
\hline 3 yrs & $4(8 \%)$ & $9(16 \%)$ & $14(25 \%)$ & $27(16 \%)$ \\
\hline 5 yrs & $5(9 \%)$ & $15(27 \%)$ & $16(28 \%)$ & $36(22 \%)$ \\
\hline 10 yrs & $6(11 \%)$ & $17(30 \%)$ & $16(28 \%)$ & $39(23 \%)$ \\
\hline \multicolumn{5}{|c|}{ Total no. of patients in GR Classes III-V at FU (\% of total) } \\
\hline $1 \mathrm{yr}$ & $0(0 \%)$ & $8(14 \%)$ & $22(39 \%)$ & $30(18 \%)$ \\
\hline 3 yrs & $0(0 \%)$ & $11(20 \%)$ & $31(54 \%)$ & $42(25 \%)$ \\
\hline 5 yrs & $0(0 \%)$ & $13(23 \%)$ & $34(60 \%)$ & $47(28 \%)$ \\
\hline 10 yrs & $1(2 \%)$ & $14(25 \%)$ & $38(67 \%)$ & $53(32 \%)$ \\
\hline \multicolumn{5}{|l|}{ Final hearing outcome, number (\%) } \\
\hline GR Class I & $46(87)$ & $24(43)$ & $3(5)$ & $73(44)$ \\
\hline GR Classes | \& || & $52(98)$ & $41(73)$ & $19(33)$ & $112(67)$ \\
\hline \multicolumn{5}{|l|}{ PTA $(\mathrm{dB})$} \\
\hline \multicolumn{5}{|l|}{ Tumor side } \\
\hline Median & 15 & 33.5 & 51 & 35 \\
\hline Range & -2 to 100 & 7 to 120 & 15 to 120 & -2 to 120 \\
\hline \multicolumn{5}{|l|}{ Nontumor side } \\
\hline Median & 8 & 10 & 10 & 10 \\
\hline Range & 0 to 29 & 0 to 38 & 0 to 30 & 0 to 38 \\
\hline \multicolumn{5}{|l|}{ Difference btwn sides } \\
\hline Median & 5 & 19 & 40 & 22 \\
\hline Range & -9 to 92 & -5 to 112 & 0 to 112 & -9 to 112 \\
\hline \multicolumn{5}{|c|}{ Difference btwn pre-SRS and post-SRS } \\
\hline Median & 5 & 13.5 & 28 & 13 \\
\hline Range & -10 to 85 & -7 to 102 & -15 to 103 & -15 to 103 \\
\hline \multicolumn{5}{|l|}{ Normal side, post - pre } \\
\hline Median & 2 & 0 & 3 & 2 \\
\hline Range & -7 to 18 & -7 to 15 & -7 to 20 & -7 to 20 \\
\hline \multicolumn{5}{|l|}{ SDS, $\%$} \\
\hline \multicolumn{5}{|l|}{ Tumor side } \\
\hline Median & 100 & 88 & 54 & 84 \\
\hline Range & 0 to 100 & 0 to 100 & 0 to 100 & 0 to 100 \\
\hline \multicolumn{5}{|l|}{ Nontumor side } \\
\hline Median & 100 & 100 & 100 & 100 \\
\hline Range & 80 to 100 & 70 to 100 & 90 to 100 & 70 to 100 \\
\hline \multicolumn{5}{|l|}{ Difference in SDS, \% } \\
\hline \multicolumn{5}{|l|}{ Tumor side, pre - post } \\
\hline Median & 0 & 8 & 40 & 8 \\
\hline Range & -12 to 100 & -16 to 100 & -20 to 100 & -20 to 100 \\
\hline
\end{tabular}

$\mathrm{FU}=$ follow-up; $\mathrm{GR}$ = Gardner-Robertson; $\mathrm{pt}$ = patient.

hearing preservation. We found that better pre-SRS hearing class (I-A) remained as the only significant factor associated with higher rates of serviceable hearing preservation following SRS ( $p<0.0001)$.

\section{Adverse Radiation Effects}

One patient without tumor growth developed symptoms of imbalance and vertigo 7 years after SRS. No pa- tient developed any other new cranial nerve deficits, including facial, trigeminal, or lower cranial nerve deficits. None of the patients developed hydrocephalus. No patient developed either clinical or imaging evidence of adverse radiation effects within the brainstem.

\section{Hearing in the Non-Tumor-Affected Ear}

The median PTA pre- and post-SRS in Class IA pa- 


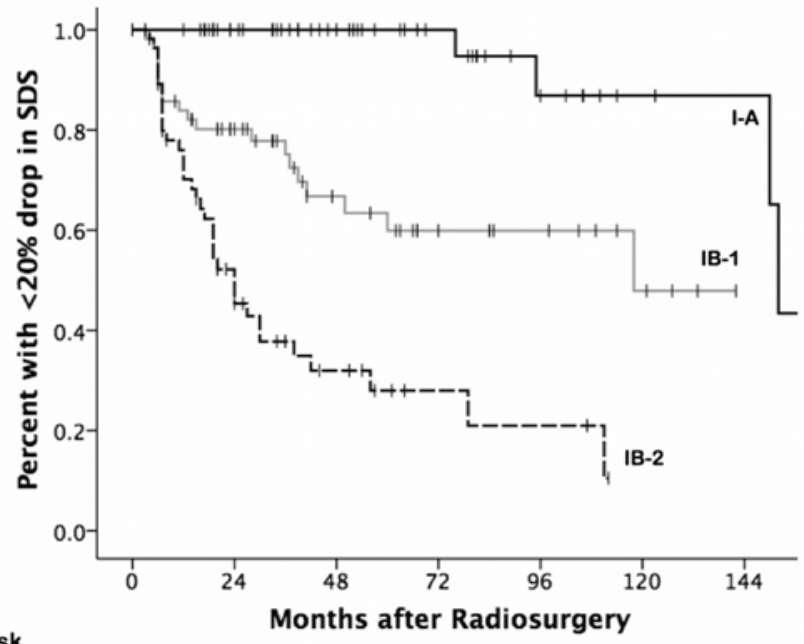

No. at Risk

$\begin{array}{llllllll}1 \mathrm{~A} & 53 & 41 & 28 & 19 & 10 & 5 & 4 \\ 1 \mathrm{B1} & 56 & 36 & 20 & 11 & 9 & 4 & - \\ 1 \mathrm{B2} & 57 & 22 & 10 & 4 & 3 & - & -\end{array}$

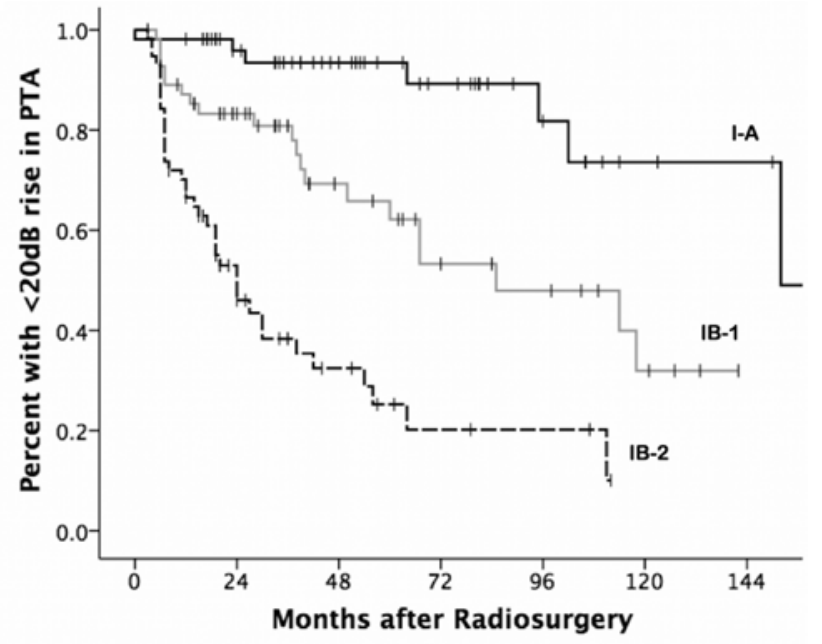

$\begin{array}{lllllll}53 & 41 & 28 & 19 & 10 & 5 & 4 \\ 56 & 36 & 20 & 11 & 9 & 4 & - \\ 57 & 22 & 10 & 4 & 3 & - & -\end{array}$

FIG. 2. Kaplan-Meier analysis of hearing changes. The Kaplan-Meier curves show the percentage of patients in Classes I-A, I-B1, and I-B2 with a $<20 \%$ decrease in SDS (166 patients, left) and $<20 \mathrm{~dB}$ elevation (166 patients, right) in PTA after SRS. I-A versus I-B1 and I-B1 versus I-B2, $p<0.0001$ (left). I-A versus I-B1, $p=0.001$; I-B1 versus I-B2, $p<0.0001$ (right).

tients was $7 \mathrm{~dB}$ versus $8 \mathrm{~dB}(\mathrm{p}=0.10)$, in Class IB-1 it was $10 \mathrm{~dB}$ in both $(\mathrm{p}=0.35)$, and for Class IB-2 it was 9 versus $10(\mathrm{p}=0.23)$. The median SDS pre- and post-SRS was $100 \%$ for all the 3 classes for the non-tumor-affected ear (details in Table 1 and 2). The only significant hearing change in the non-tumor-affected ear was noted in 1

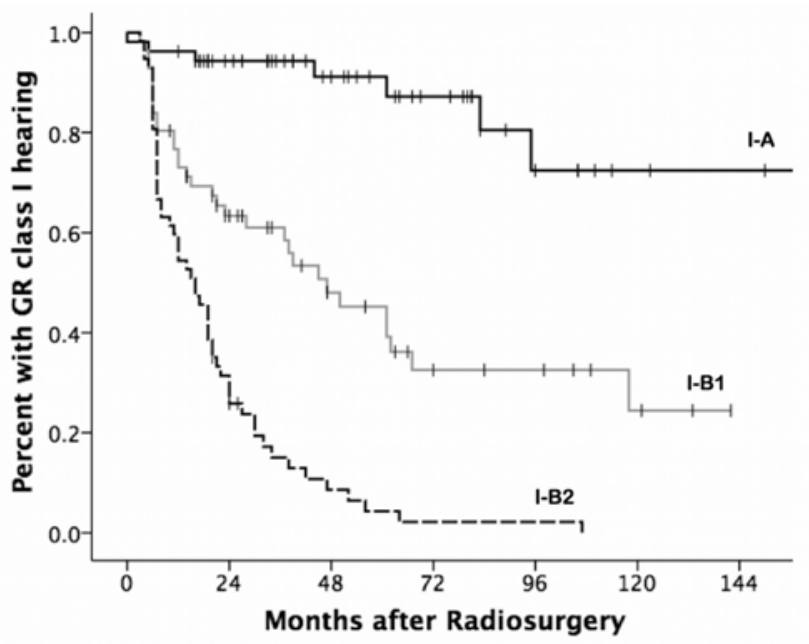

No. at Risk

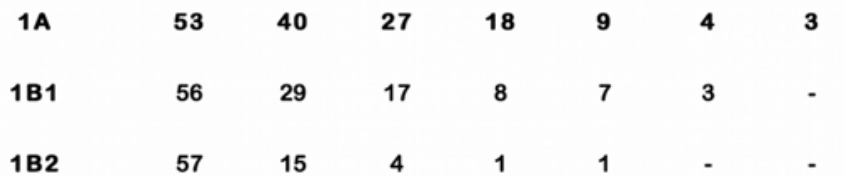

patient. In this patient PTA changed from $23 \mathrm{~dB}$ to $38 \mathrm{~dB}$ 10.5 years after SRS.

\section{Discussion}

Over the past 2 decades, SRS has become one of the

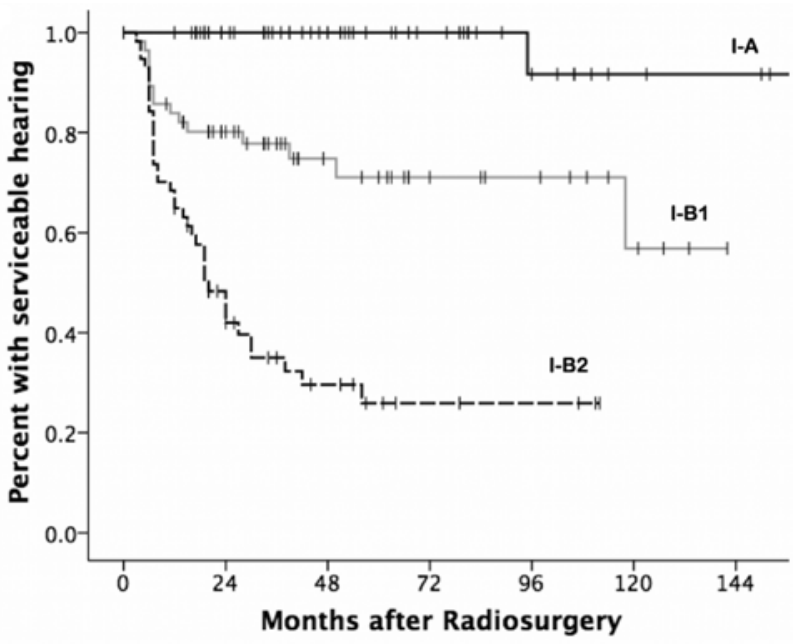

$\begin{array}{lllllll}53 & 41 & 28 & 19 & 10 & 5 & 4 \\ 56 & 36 & 20 & 11 & 9 & 4 & - \\ 57 & 21 & 10 & 4 & 3 & - & -\end{array}$

FIG. 3. Kaplan-Meier analysis of preservation of hearing. The graph shows the percentage of patients with Gardner-Robertson Class I (166 patients, left) hearing and serviceable (166 patients, right) hearing after SRS. The Kaplan-Meier curves have been stratified into 3 groups based on Gardner-Robertson Class I subclass prior to SRS. I-A versus I-B1 and I-B1 versus I-B2, $p<$ 0.0001 (left). I-A versus I-B1 and I-B1 versus I-B2, $p<0.0001$ (right). 
most common management strategies for small and medium sized vestibular schwannomas., ${ }^{4,12,16,19,27}$ Despite variations in technologies, fractionation, delivery techniques, dose delivered, conformality of 3D dose delivery, and selectivity (fall off outside the tumor volume), focused radiation has become an important management option across the world. Previous studies demonstrated that despite variations in methods and technologies, sustained tumor growth control was obtained in $90 \%-98 \%$ of patients. ${ }^{11,13,22}$ Complications previously noted with microsurgical management have been virtually eliminated. ${ }^{10}$ Despite the high tumor control rates, long-term serviceable hearing preservation rates vary from $60 \%$ to $90 \%$, depending on the classification system used and the proportion of patients with normal pre-SRS hearing., $7,13,18,21$

Some physicians advocate an initial observation interval ("wait and scan" approach) due to the purported slow growth rate of vestibular schwannomas. The effect of delayed intervention on hearing preservation rates has been studied sparingly. ${ }^{8,9,17,20,26}$ In contrast, recent studies have reported that SRS is associated with high-level hearing preservation rates. ${ }^{12,18}$ In our current study, we found that SRS preserves functional hearing at 10 years in up to $98 \%$ of patients treated prior to the development of subjective hearing loss.

To analyze long-term hearing preservation rates in patients who present with "normal" hearing (Gardner-Robertson Class I), we devised a subclassification system. Patients without subjective hearing loss tend to maintain optimal hearing levels and were assigned to Class I-A. Patients who experienced mild subjective hearing loss prior to SRS were assigned to Class I-B. Class I-B was further stratified into 2 classes. Since the PTA in the general population varies significantly ${ }^{2}$ and in our studied population ranged from 0 to $25 \mathrm{~dB}$ in the non-tumor-affected ear, we used the non-tumor-affected ear hearing as a control. If the difference in PTA between the 2 ears was $10 \mathrm{~dB}$ or less, patients were assigned Class I-B1, and if the difference was greater than $10 \mathrm{~dB}$, patients were assigned Class I-B2. This subclassification system provided a better prediction of hearing preservation in each patient based on his/her hearing in the non-tumor-affected ear.

We realized that the adjustment of observed effects in our nonrandomized study was a critical part of data analysis because confounding influences of covariates could bias effect estimates. The concern was that there might be other factors that were responsible for better hearing preservation that were included in Class I-A. To determine whether a bias that caused good responders to be grouped in Class I-A was present, we created a propensity score for the probability of being in a better pre-SRS hearing class (I-A) with the intention of adding it to the multivariate analysis for serviceable hearing preservation. We found that females and younger patients were significantly more likely to be treated using SRS while they still had Class I-A hearing. When propensity scores were constructed for females and younger patients (then added to the Cox proportional hazards model for serviceable hearing preservation), better pre-SRS hearing class (I-A) remained as the only significant factor associated with higher rates of serviceable hearing preservation following SRS $(\mathrm{p}<0.0001)$.
Despite our promising findings, this retrospective analysis of our vestibular schwannoma data registry has limitations, including a lack of a control group (observation alone). The SRS procedure and follow-up were performed by the same physicians throughout the study. In the future a prospective randomized clinical trial that evaluates patients with Class I-A hearing who undergo either SRS or observational management may provide a higher level of evidence to guide further management recommendations.

\section{Conclusions}

We found that hearing preservation in patients with small vestibular schwannomas and pre-SRS normal hearing (Gardner-Robertson Class I) was significantly better if SRS was performed before subjective hearing loss was reported. In patients who reported subjective hearing loss, the difference in PTA between the affected ear and the unaffected ear was an important factor in long-term hearing preservation. We believe that higher levels of hearing preservations noted in this study, coupled with long-term tumor control, and the absence of additional cranial nerve disorders may warrant earlier SRS rather than observation of newly diagnosed vestibular schwannomas.

\section{Acknowledgments}

We gratefully thank Josh M. Mindin, BS, Kenneth Goodrich, BS, and Matthew Gable, BS, of the University of Pittsburgh for their contribution in identifying patients for data entry.

\section{References}

1. Berkowitz O, Kondziolka D, Bissonette D, Niranjan A, Kano H, Lunsford LD: The evolution of a clinical registry during 25 years of experience with Gamma Knife radiosurgery in Pittsburgh. Neurosurg Focus 34(1):E4, 2013

2. Brant LJ, Fozard JL: Age changes in pure-tone hearing thresholds in a longitudinal study of normal human aging. $\mathbf{J}$ Acoust Soc Am 88:813-820, 1990

3. Flickinger JC, Kondziolka D, Niranjan A, Maitz A, Voynov G, Lunsford LD: Acoustic neuroma radiosurgery with marginal tumor doses of 12 to 13 Gy. Int J Radiat Oncol Biol Phys 60:225-230, 2004

4. Flickinger JC, Lunsford LD, Coffey RJ, Linskey ME, Bissonette DJ, Maitz AH, et al: Radiosurgery of acoustic neurinomas. Cancer 67:345-353, 1991

5. Gardner G, Robertson JH: Hearing preservation in unilateral acoustic neuroma surgery. Ann Otol Rhinol Laryngol 97:55-66, 1988

6. Gordon ML, Cohen NL: Efficacy of auditory brainstem response as a screening test for small acoustic neuromas. Am J Otol 16:136-139, 1995

7. Hajioff D, Raut VV, Walsh RM, Bath AP, Bance ML, Guha A, et al: Conservative management of vestibular schwannomas: third review of a 10-year prospective study. Clin Otolaryngol 33:255-259, 2008

8. Hasegawa T, Kida Y, Kobayashi T, Yoshimoto M, Mori Y, Yoshida J: Long-term outcomes in patients with vestibular schwannomas treated using gamma knife surgery: 10-year follow up. J Neurosurg 102:10-16, 2005

9. Hoistad DL, Melnik G, Mamikoglu B, Battista R, O'Connor CA, Wiet RJ: Update on conservative management of acoustic neuroma. Otol Neurotol 22:682-685, 2001

10. Iwai Y, Yamanaka K, Shiotani M, Uyama T: Radiosurgery 
for acoustic neuromas: results of low-dose treatment. Neurosurgery 53:282-288, 2003

11. Kim KM, Park CK, Chung HT, Paek SH, Jung HW, Kim DG: Long-term outcomes of Gamma knife stereotactic radiosurgery of vestibular schwannomas. J Korean Neurosurg Soc 42:286-292, 2007

12. Kondziolka D, Lunsford LD, McLaughlin MR, Flickinger JC: Long-term outcomes after radiosurgery for acoustic neuromas. N Engl J Med 339:1426-1433, 1998

13. Kondziolka D, Mousavi SH, Kano H, Flickinger JC, Lunsford LD: The newly diagnosed vestibular schwannoma: radiosurgery, resection, or observation? Neurosurg Focus 33(3):E8, 2012

14. Lin D, Hegarty JL, Fischbein NJ, Jackler RK: The prevalence of "incidental" acoustic neuroma. Arch Otolaryngol Head Neck Surg 131:241-244, 2005

15. Linskey ME, Lunsford LD, Flickinger JC: Neuroimaging of acoustic nerve sheath tumors after stereotaxic radiosurgery. AJNR Am J Neuroradiol 12:1165-1175, 1991

16. Lunsford LD: Foreword. Acoustic neuroma. Prog Neurol Surg 21:XI-XV, 2008

17. Martin TP, Senthil L, Chavda SV, Walsh R, Irving RM: A protocol for the conservative management of vestibular schwannomas. Otol Neurotol 30:381-385, 2009

18. Mousavi SH, Kano H, Faraji AH, Gande A, Flickinger JC, Niranjan A, et al: Hearing preservation up to 3 years after gamma knife radiosurgery for Gardner-Robertson class I patients with vestibular Schwannomas. Neurosurgery 76:584-591, 2015

19. Patel J, Vasan R, van Loveren H, Downes K, Agazzi S: The changing face of acoustic neuroma management in the USA: analysis of the 1998 and 2008 patient surveys from the acoustic neuroma association. Br J Neurosurg 28:20-24, 2014

20. Raut VV, Walsh RM, Bath AP, Bance ML, Guha A, Tator $\mathrm{CH}$, et al: Conservative management of vestibular schwannomas - second review of a prospective longitudinal study. Clin Otolaryngol Allied Sci 29:505-514, 2004

21. Régis J, Pellet W, Delsanti C, Dufour H, Roche PH, Thomassin JM, et al: Functional outcome after gamma knife surgery or microsurgery for vestibular schwannomas. J Neurosurg 97:1091-1100, 2002

22. Rowe JG, Radatz MW, Walton L, Hampshire A, Seaman S, Kemeny AA: Gamma knife stereotactic radiosurgery for unilateral acoustic neuromas. J Neurol Neurosurg Psychiatry 74:1536-1542, 2003
23. Stangerup SE, Caye-Thomasen P, Tos M, Thomsen J: The natural history of vestibular schwannoma. Otol Neurotol 27:547-552, 2006

24. Subach BR, Kondziolka D, Lunsford LD, Bissonette DJ, Flickinger JC, Maitz AH: Stereotactic radiosurgery in the management of acoustic neuromas associated with neurofibromatosis Type 2. J Neurosurg 119 Suppl:815-822, 2013

25. Tamura M, Carron R, Yomo S, Arkha Y, Muraciolle X, Porcheron D, et al: Hearing preservation after gamma knife radiosurgery for vestibular schwannomas presenting with high-level hearing. Neurosurgery 64:289-296, 2009

26. Varughese JK, Breivik CN, Wentzel-Larsen T, Lund-Johansen M: Growth of untreated vestibular schwannoma: a prospective study. J Neurosurg 116:706-712, 2012

27. Williams BJ, Xu Z, Salvetti DJ, McNeill IT, Larner J, Sheehan JP: Gamma Knife surgery for large vestibular schwannomas: a single-center retrospective case-matched comparison assessing the effect of lesion size. J Neurosurg 119:463-471, 2013

\section{Disclosures}

Dr. Lunsford reports that he is a consultant for Elekta AB, Insightec DSMB, and Best Doctors; has direct stock ownership in Elekta $A B$; and is chair/founder of the International Gamma Knife Research Foundation (a nonprofit research organization).

\section{Author Contributions}

Conception and design: Mousavi, Lunsford, Niranjan. Acquisition of data: Mousavi, Akpinar, Huang, Tonetti. Analysis and interpretation of data: Niranjan, Mousavi, Tonetti, Flickinger. Drafting the article: Mousavi, Akpinar, Huang, Tonetti. Critically revising the article: Mousavi, Lunsford, Flickinger, Niranjan. Reviewed submitted version of manuscript: all authors. Approved the final version of the manuscript on behalf of all authors: Niranjan. Statistical analysis: Mousavi, Niranjan, Flickinger, Kano.

\section{Correspondence}

Ajay Niranjan, Department of Neurosurgery, University of Pittsburgh, 200 Lothrop St., Ste. B-400, Pittsburgh, PA 15213. email: niranjana@upmc.edu. 